\title{
Substituição do Milho pela Farinha de Varredura (Manihot esculenta, Crantz) na Ração de Bezerros Holandeses. 1. Desempenho e Parâmetros Sangüíneos ${ }^{1}$
}

\author{
João Ricardo Vieira Jorge ${ }^{2}$, Lúcia Maria Zeoula ${ }^{3}$, Ivanor Nunes do Prado³, Luiz Juliano Valério Geron ${ }^{4}$
}

\begin{abstract}
RESUMO - O objetivo deste trabalho foi avaliar o efeito de diferentes níveis de substituição do milho pela farinha de varredura de mandioca $(0,25,50,75$ e 100\%, base da matéria seca), sobre o consumo e conversão alimentar, ganho médio diário e níveis de hematócrito, glicose e uréia sanguíneos. Utilizaram-se 35 bezerros holandeses puros de origem ou puros por cruzamento, não castrados, com idade aproximada de 80 dias e peso vivo médio de $80 \mathrm{~kg}$, distribuídos em delineamento de blocos casualizados. Os animais foram alimentados à vontade, até atingir o consumo de $4 \mathrm{~kg}$ /dia de concentrado. Como volumoso, foi utilizado feno inteiro de capim tifton 85 . Os animais terminaram o experimento, com peso médio de $164 \mathrm{~kg}$. A elevação dos níveis de substituição ocasionou uma resposta linear decrescente no consumo de matéria seca. A conversão alimentar não diferiu entre os tratamentos. Os ganhos diários para os dois primeiros períodos de 28 dias reduziram-se linearmente, com a elevação dos níveis de substituição, mas não diferiram no último período de 28 dias, apresentando valores estimados, variando de 0,93 a 0,68, 1,10 a 0,89 e 1,09 kg/dia, respectivamente. Os níveis de hematócrito, glicose e uréia não foram influenciados pelos níveis de substituição do milho pela farinha de varredura.
\end{abstract}

Palavras-chave: bezerros, consumo, conversão alimentar, ganho de peso, mandioca, plasma ${ }^{1}$

\section{Replacement of Corn for Cassava Meal (Manihot esculenta, Crantz) in the Holstein Calves Diets. 1. Performance and Blood Parameters}

\begin{abstract}
The objective of this project was to evaluate the effects of different replacement levels of corn for cassava meal ( 0 , $25,50,75$, and $100 \%$, dry matter basis) on the dry matter intake and feed:gain ratio, daily weight gain and levels of blood hematocrit, glucose and urea. Thirty five intact Holstein calves, averaging 80 days old and initial live weight of $80 \mathrm{~kg}$, were allotted to a randomized block design and fed concentrate, ad libitum, to reach the intake of $4 \mathrm{~kg} / \mathrm{day}$. Tifton 85 bermudagrass was fed as roughage. The final average weight was of $164 \mathrm{~kg}$. The dry matter intake showed a linear behavior as the replacement levels increased. The feed:gain ratio was not affected by the replacement levels. The daily weight gain for the two first periods of 28 days (period 1 and 2 , respectively) reduced as the replacement levels increased, but they were not affected in the last 28 days period (period 3 ), and the respective values ranged from 0.93 to $0.68,1.10$ to 0.89 , and $1.09 \mathrm{~kg} /$ day. Levels of hematocrit, glucose and urea were not affected by the replacement of corn for cassava meal.
\end{abstract}

Key Words: calves, cassava, feed:gain ratio, intake, plasma, weight gain

\section{Introdução}

A criação dos machos de plantéis leiteiros para abate precoce é viável, mas depende dos preços de mercado. Todavia, esta deverá ser tanto mais intensiva, quanto maior for a proporção de sangue europeu dos animais (Lucci, 1989). Deve-se salientar que a produtividade desses animais é conseqüência da complexa interação entre a dieta, sua preparação e seu valor nutritivo, que determinam o consumo de nutrientes e a eficiência com que tais nutrientes são utilizados nos processos metabólicos.

Para que se consiga êxito na criação de machos de plantéis leiteiros, é preciso direcionar estudos para os aspectos nutricionais, para que esses animais utilizem o mínimo de leite, sendo desaleitados precocemente e, também, utilizem alimentos de baixo custo, disponíveis na região, levando-se em consideração, ainda, os aspectos de manejo e condições sanitárias.

A principal vantagem de novilhos holandeses sobre outras raças tradicionais para o corte está no seu desempenho uniforme. A raça holandesa tem sido selecionada, principalmente, para altas produções de leite. Esta seleção resultou em uma base genética relativamente estreita, comparada com raças especializadas para corte, que acarretou para os

\footnotetext{
${ }_{1}^{1}$ Parte da dissertação de mestrado em Zootecnia, apresentada pelo primeiro autor à UEM.

2 Mestre em Zootecnia, PPZ, UEM - Rua Tomé de Sousa, 195, zona 2, CEP 87010-380 Maringá, PR. E.mail: jricardo@wnet.com.br

${ }^{3}$ Professores do PPZ/UEM, Bolsistas pesquisadores, CNPq - UEM - Av. Colombo, 5790 - CEP 87020-900. E.mail: Imzeoula@uem.br; inprado@uem.br.

${ }^{4}$ Bolsista de iniciação científica - CNPq. E.mail: ljgeron@yahoo.com.br
} 
novilhos holandeses, em um consumo alimentar e ganho diário mais consistentes e previsíveis ao longo do período alimentar, tornando mais fácil o manejo nutricional (Grant et al., 1993).

A literatura mostra que, se os animais tiverem acesso a um manejo correto quanto aos aspectos nutricionais e sanitários, eles podem atingir $200 \mathrm{~kg}$ de $\mathrm{PV}$, aos seis meses de idade, com ganhos diários de até $1,40 \mathrm{~kg} / \mathrm{dia}$. Lucci et al. (1974), citados por Lucci (1989), forneceram uma mistura concentrada com $20 \%$ de proteína e feno de capim gordura de baixa qualidade, à vontade e verificaram ganho diário de $0,70 \mathrm{~kg} / \mathrm{dia}$, atingindo-se $143 \mathrm{~kg}$ aos 180 dias. Salles \& Lucci (1998) avaliaram o desempenho de bezerros holandese submetidos a níveis de monensina sódica, visando altos ganhos e encontraram resposta quadrática para o ganho de peso $(1,1 \mathrm{a} 1,4 \mathrm{~kg} / \mathrm{dia})$. Araújo et al. (1998) alimentaram bezerros holandeses com feno de capim coastcross (de 10 a $55 \%$ de inclusão) e concentrado e obtiveram ganho diário variando de 1,0 a $0,7 \mathrm{~kg} / \mathrm{dia}$, abatendo estes animais com $180 \mathrm{~kg}$ de peso vivo. Campos \& Lizieire (2000), utilizando um sistema intensivo de alimentação, fornecendo, em média, 5,5 kg de concentrado/animal/dia no final do período experimental, obtiveram bezerros holandeses com seis meses de idade e peso vivo médio de $196 \mathrm{~kg}$.

A mandioca e seus resíduos podem ser fontes alternativas de energia, visto que os grãos mais nobres são utilizados na alimentação humana e de animais não ruminantes, que apresentam melhor resposta à utilização deste tipo de alimento. Todavia, os dados referentes ao uso de mandioca e seus resíduos, em substituição parcial ou total dos alimentos tradicionalmente usados na alimentação de bovinos, são escassos e pouco conclusivos (Marques et al., 2000).

A farinha de varredura é um resíduo que se origina da limpeza das farinheiras, contendo, principalmente, farinha suja (imprópria para o consumo humano), e apresenta elevado teor de amido (80\%) e de matéria seca (90\%). De acordo com estas informações, a mandioca e seus resíduos podem ser classificados como fontes energéticas (Caldas Neto et al., 2000). Todavia, os valores da composição química da raiz de mandioca e seus resíduos não são homogêneos e padronizados, como para os alimentos clássicos utilizados na alimentação animal (Melotti, 1972; De Bem, 1996; Martins et al., 1999). Segundo Cereda (1994), esta variação ocorre devido a diversos fatores, como nível tecnológico da indústria, qualidade da mão-de-obra e variedades de mandioca.

A substituição de milho por farinha de mandioca, na proporção de 50 e $100 \%$, foi fornecida na alimentação de bezerros da raça Holandesa (Peixoto \& Warner, 1993). O tratamento com $100 \%$ de substituição apresentou ganhos de peso menores e, segundo os autores, o menor desempenho dos animais foi devido ao menor consumo de ração, pois a farinha de mandioca é quase sem gosto, muito pulverulenta e seca. Desta forma, os animais não mastigam a farinha da mesma forma como fariam com o milho grosseiro. Reduções no consumo também foi observado por Marques et al. (2000) para novilhas, recebendo rações com farinha de varredura, em substituição total ao milho.

Devido à escassez de informações sobre o desempenho ou a criação de machos provenientes de rebanhos leiteiros e do uso de resíduos das farinheiras, este trabalho teve por objetivo avaliar o desempenho, consumo e conversão alimentar e níveis de hematócrito, glicose e uréia sanguíneos de bezerros holandeses, alimentados com dietas, contendo níveis crescentes de farinha de varredura, em substituição ao milho.

\section{Material e Métodos}

O experimento foi realizado em uma propriedade particular, denominada Fazenda Clicie, situada no município de São João de Caiuá, no noroeste do Paraná, e no Laboratório de Nutrição Animal do Departamento de Zootecnia (DZO) da Universidade Estadual de Maringá.

O experimento foi desenvolvido no período de abril a novembro de 1999.

Do nascimento até 164 dias de idade, os bezerros foram mantidos em bezerreiros individuais, construídos em madeira e teto de zinco, com dimensões de $1,10 \mathrm{x}$ 1,50 metros. Cada animal dispunha de cocho para o fornecimento de ração, fenil e balde para a água e leite.

Foram utilizados 35 bezerros, machos, puros de origem (PO) ou puros por cruzamento (PC), da raça Holandesa $\mathrm{P} \& \mathrm{~B}$, recém-nascidos, com peso médio inicial de $40 \mathrm{~kg}$, provenientes da propriedade ou de rebanhos em bom estado sanitário, de granjas leiteiras da região de Maringá. Esses animais receberam dieta e manejo semelhantes, do nascimento ao desaleitamento (período pré-experimental), quando após iniciou-se o período experimental.

Durante o período de aleitamento, os animais 
receberam 4 litros diários de leite integral e uma alimentação ad libitum, a partir do $7^{\circ}$ dia de vida, constituída por um concentrado comercial peletizado, que continha $20,7 \%$ de proteína bruta, $1,7 \%$ de cálcio e $0,57 \%$ de fósforo e feno integral de capim Tifton 85 , um híbrido de Cynodon dactylum (L) Pers.

O leite integral fornecido aos bezerros foi proveniente do rebanho da propriedade e composto por leite recentemente ordenhado, leite de animais com mastite, leite de animais tratados com antibióticos e colostro excedente, dependendo da disponibilidade destes. Todas as fontes foram homogeneizadas, para depois ser o leite fornecido aos animais, entre 36 e $38^{\circ} \mathrm{C}$.

A partir dos sete dias de idade, foi fornecida água de boa qualidade, advinda de poço artesiano. O fornecimento foi à vontade, em baldes plásticos, fixados no lado de fora dos bezerreiros, sempre duas horas após o aleitamento. Os baldes foram vistoriados de duas em duas horas, para o seu abastecimento.

Após a desmama, os bezerros receberam dietas distintas, constituídas de farelo de soja (FS), milho integral triturado $(\mathrm{M})$, farinha de varredura de mandioca (FM), farinha de peixe (FP), feno de Tifton 85 triturado (FT) e sal suplementado com minerais e vitaminas (para cada kg, Ca - $230 \mathrm{~g}, \mathrm{P}-90 \mathrm{~g}, \mathrm{Mg}-$ $20 \mathrm{~g}, \mathrm{~S}-15 \mathrm{~g}, \mathrm{~F}-0,9 \mathrm{~g}, \mathrm{Cu}-700 \mathrm{mg}, \mathrm{Zn}-2.700 \mathrm{mg}$, $\mathrm{Mn}-1.250 \mathrm{mg}, \mathrm{Fe}-2.000 \mathrm{mg}, \mathrm{I}-80 \mathrm{mg}$, Co - 100 $\mathrm{mg}$, Se - $20 \mathrm{mg}$, vitamina A - $200.000 \mathrm{UI}$, vitamina D3 - 60.000 UI e vitamina E - 60 UI) . O feno de capim tifton 85 foi utilizado como volumoso, na forma integral, e triturado, fazendo parte dos con- centrados. A composição química dos alimentos utilizados é mostrada na Tabela 1.

As rações foram isoenergéticas, isoprotéicas, isocálcicas e isofosfóricas, seguindo as exigências nutricionais, recomendados pela Embrapa - CNPGL, segundo Campos \& Lizieire (2000), para bezerros desmamados, até 180 dias de idade. As rações foram formuladas, substituindo o milho pela farinha de varredura $(\mathrm{FV})$, em níveis crescentes de $0,25,50,75$ e $100 \%$. As rações foram peletizadas e fornecidas duas vezes ao dia, às 8 e $16 \mathrm{~h}$. e ajustadas para o fornecimento de $10 \%$ acima do consumo voluntário. Os animais, quando atingiram 120 dias de idade, passaram a receber rações experimentais não peletizadas e ajustadas para seus requerimentos nutricionais (Tabela 2), duas vezes ao dia, restringindo-se a um máximo de $4 \mathrm{~kg}$ de concentrado/animal/dia. $\mathrm{O}$ feno foi fornecido ad libitum, sendo trocado a cada três dias, ou quando da falta deste.

Nas Tabelas 2 e 3, encontram-se as composições percentual e química das rações experimentais, correspondentes ao período da desmama, até 120 dias de idade e de 121 até 180 dias de idade, respectivamente.

Os animais nascidos na propriedade foram pesados por ocasião do nascimento e receberam um brinco de identificação. O manejo até ao desaleitamento foi:

1. Separação das mães, 24 horas após o nascimento;

2. Do $2^{\circ}$ ao $3^{\circ}$ dia, quatro litros de colostro, em baldes, duas vezes ao dia, às 8 e $16 \mathrm{~h}$;

3. Do $4^{\circ}$ dia até ao desaleitamento, 4 litros de leite,

Tabela 1 - Composição química dos alimentos

Table 1 - Chemical composition of the ingredients

\begin{tabular}{|c|c|c|c|c|c|c|}
\hline $\begin{array}{l}\text { Alimentos } \\
\text { Feeds }\end{array}$ & $\begin{array}{l}\% \mathrm{MS}^{1} \\
\% D M^{1}\end{array}$ & $\begin{array}{l}\% \mathrm{~PB}^{1^{*}} \\
\% C P^{*}\end{array}$ & $\begin{array}{l}\% \mathrm{FDN}^{1 *} \\
\% \mathrm{NDF}^{1 *}\end{array}$ & $\begin{array}{l}\% \mathrm{AMIDO}^{*} \\
\% \text { STARCH}\end{array}$ & $\begin{array}{l}\mathrm{ELm}^{2} \\
\mathrm{Nem}^{2}\end{array}$ & $\begin{array}{l}\mathrm{ELg}^{2} \\
\mathrm{Neg}^{2}\end{array}$ \\
\hline $\begin{array}{l}\text { Milho } \\
\text { Corn }\end{array}$ & 88,0 & 9,4 & 11,4 & 73,5 & 2.013 & 1.357 \\
\hline $\begin{array}{l}\text { Farinha de varredura } \\
\text { Cassava meal }\end{array}$ & 90,7 & 1,5 & 10,4 & 85,7 & 1.974 & 1.328 \\
\hline $\begin{array}{l}\text { Farelo de soja } \\
\text { Soybean meal }\end{array}$ & 88,4 & 49,4 & 15,1 & 3,5 & 2.001 & 1.348 \\
\hline $\begin{array}{l}\text { Feno de tifton } 85 \\
\text { Tifton } 85 \text { hay }\end{array}$ & 90,0 & 10,0 & 76,2 & 4,2 & 900 & 350 \\
\hline Farinha de peixe & 90,5 & 60,0 & - & - & 1.730 & 1.110 \\
\hline
\end{tabular}

Fish meal

* \% de matéria seca;

1 MS - matéria seca, PB - proteína bruta e FDN - fibra em detergente neutro.

2 ELm - energia líquida de mantença (kcal/kg) e ELg - energia líquida de ganho (kcal/kg), segundo Kearl (1982).

* \% dry matter.

1 DM - dry matter, CP - crude protein and NDF - neutral detergent fiber.

$2 \mathrm{NEm}$ - net energy for maintenance ( $\mathrm{kcal} / \mathrm{kg})$ and NEg - net energy for gain ( $\mathrm{kcal} / \mathrm{kg})$ according to Kearl (1982). 
Tabela 2 - Composição percentual e química dos concentrados experimentais para o período do desaleitamento até 120 dias de idade

Table 2 - Percentual and chemical composition of the experimental concentrates for the period from weaning to 120 days old

\begin{tabular}{|c|c|c|c|c|c|}
\hline \multirow[t]{2}{*}{$\begin{array}{l}\text { Variáveis } \\
\text { Variables }\end{array}$} & \multicolumn{5}{|c|}{$\begin{array}{l}\text { Nível de substituição (\%) } \\
\text { Replacement level (\%) }\end{array}$} \\
\hline & 0 & 25 & 50 & 75 & 100 \\
\hline $\begin{array}{l}\text { Milho } \\
\text { Corn }\end{array}$ & 75,40 & 56,55 & 37,70 & 18,85 & - \\
\hline $\begin{array}{l}\text { Farinha de varredura } \\
\text { Cassava meal }\end{array}$ & - & 18,85 & 37,70 & 55,91 & 72,17 \\
\hline $\begin{array}{l}\text { Farelo de soja } \\
\text { Soybean meal }\end{array}$ & 11,90 & 13,11 & 14,33 & 16,04 & 19,26 \\
\hline $\begin{array}{l}\text { Feno de tifton } 85 \\
\text { Tifton } 85 \text { bermudagrass hay }\end{array}$ & 7,71 & 6,13 & 4,55 & 3,21 & 2,57 \\
\hline $\begin{array}{l}\text { Farinha de peixe } \\
\text { Fish meal }\end{array}$ & 1,50 & 1,50 & 1,50 & 1,50 & 1,50 \\
\hline $\begin{array}{l}\text { Suplemento mineral e vit. } \\
\text { Mineral and vit. suppl. }\end{array}$ & 2,00 & 2,00 & 2,00 & 2,00 & 2,00 \\
\hline $\begin{array}{l}\text { Uréia } \\
\text { Urea }\end{array}$ & - & 0,36 & 0,73 & 1,00 & 1,00 \\
\hline $\begin{array}{l}\text { Calcário } \\
\text { Limestone }\end{array}$ & 0,75 & 0,75 & 0,75 & 0,75 & 0,75 \\
\hline $\begin{array}{l}\text { Fosfato bicálcico } \\
\text { Dicalcium phosphate }\end{array}$ & 0,45 & 0,45 & 0,45 & 0,45 & 0,45 \\
\hline $\begin{array}{l}\text { Sal comum } \\
\text { Salt }\end{array}$ & 0,29 & 0,29 & 0,29 & 0,29 & 0,29 \\
\hline Total & 100 & 100 & 100 & 100 & 100 \\
\hline $\begin{array}{l}\text { Matéria seca (\%) } \\
\text { Dry matter }(\%)\end{array}$ & 87,71 & 88,30 & 88,93 & 89,42 & 90,00 \\
\hline $\begin{array}{l}\text { Proteína bruta }(\%) \\
\text { Crude protein }(\%)\end{array}$ & 14,60 & 14,60 & 14,60 & 14,60 & 14,60 \\
\hline $\begin{array}{l}\text { Proteína degrad. rúmen }{ }^{1}(\%) \\
\text { Ruminal degradable protein }{ }^{1}(\%)\end{array}$ & 7,78 & 8,48 & 9,17 & 9,77 & 10,10 \\
\hline $\begin{array}{l}\text { Proteína não degrad. rúmen } 1(\%) \\
\text { Ruminal undegradable protein } 1(\%)\end{array}$ & 6,82 & 6,12 & 5,43 & 4,83 & 4,50 \\
\hline $\begin{array}{l}\text { NDT }(\%) \\
T D N(\%)\end{array}$ & 76,60 & 76,60 & 76,60 & 76,60 & 76,60 \\
\hline $\begin{array}{l}\operatorname{ELm}(\mathrm{kcal} / \mathrm{kg}) \\
N E m(k c a l / k g)\end{array}$ & 1.825 & 1.828 & 1.831 & 1.833 & 1.833 \\
\hline $\begin{array}{l}\mathrm{ELg}(\mathrm{kcal} / \mathrm{kg}) \\
N E g(\mathrm{kcal} / \mathrm{kg})\end{array}$ & 1.191 & 1.193 & 1.196 & 1.198 & 1.198 \\
\hline $\begin{array}{l}\text { FDN }(\%) \\
N D F(\%)\end{array}$ & 16,27 & 15,06 & 13,85 & 12,83 & 12,37 \\
\hline $\begin{array}{l}\text { Cálcio }^{2}(\%) \\
\text { Calcium }^{2}(\%)\end{array}$ & 0,92 & 0,92 & 0,92 & 0,92 & 0,92 \\
\hline $\begin{array}{l}\text { Fósforo } 2(\%) \\
\text { Phosphorus }^{2}(\%)\end{array}$ & 0,58 & 0,58 & 0,58 & 0,58 & 0,58 \\
\hline
\end{tabular}

1 Segundo dados do NRC (1988).

2 Teores da suplementação mineral.

${ }^{1}$ According to data from NRC (1988).

2 Levels from mineral supplementation.

duas vezes ao dia, às 8 e $16 \mathrm{~h}$;

4. Do $7^{\circ}$ dia até ao desaleitamento, concentrado comercial, com $20,7 \%$ de proteína bruta, $1,7 \%$ de cálcio e $0,57 \%$ de fósforo, ad libitum,

5. Do $7^{\circ}$ dia até ao desaleitamento, feno inteiro ad libitum.

Um pouco do concentrado foi colocada no fundo do balde, por ocasião do final de cada aleitamento, para estimular o animal a ingeri-lo, evitando maiores discrepâncias no consumo (Noller et al. 1975, citados por Prado, 1981), ocasionadas por diferentes comportamentos dos animais.

Os animais provenientes de outras granjas leiteiras (20 animais) foram selecionados e transportados 
Tabela 3 - Composição percentual e química dos concentrados experimentais para o período de 121 a 180 dias de idade Table 3 - Percentual and chemical composition of the experimental concentrates for the period from 121 to 180 days old

\begin{tabular}{|c|c|c|c|c|c|}
\hline \multirow[t]{2}{*}{$\begin{array}{l}\text { Variáveis } \\
\text { Variables }\end{array}$} & \multicolumn{5}{|c|}{$\begin{array}{l}\text { Nível de substituição (\%) } \\
\text { Replacement level (\%) }\end{array}$} \\
\hline & 0 & 25 & 50 & 75 & 100 \\
\hline $\begin{array}{l}\text { Milho } \\
\text { Corn }\end{array}$ & 78,41 & 58,80 & 39,20 & 19,65 & - \\
\hline $\begin{array}{l}\text { Farinha de varredura } \\
\text { Cassava meal }\end{array}$ & - & 19,60 & 39,20 & 57,85 & 74,77 \\
\hline $\begin{array}{l}\text { Farelo de soja } \\
\text { Soybean meal }\end{array}$ & 9,15 & 10,42 & 11,69 & 13,68 & 17,03 \\
\hline $\begin{array}{l}\text { Feno de tifton } 85 \\
\text { Tifton } 85 \text { bermudagrass hay }\end{array}$ & 7,45 & 5,81 & 4,17 & 2,87 & 2,21 \\
\hline $\begin{array}{l}\text { Farinha de peixe } \\
\text { Fish meal }\end{array}$ & 1,50 & 1,50 & 1,50 & 1,50 & 1,50 \\
\hline $\begin{array}{l}\text { Suplemento mineral e vit. } \\
\text { Mineral and vit. suppl. }\end{array}$ & 2,00 & 2,00 & 2,00 & 2,00 & 2,00 \\
\hline $\begin{array}{l}\text { Uréia } \\
\text { Urea }\end{array}$ & - & 0,38 & 0,76 & 1,00 & 1,00 \\
\hline $\begin{array}{l}\text { Calcário } \\
\text { Limestone }\end{array}$ & 0,75 & 0,75 & 0,75 & 0,75 & 0,75 \\
\hline $\begin{array}{l}\text { Fosfato bicálcico } \\
\text { Dicalcium phosphate }\end{array}$ & 0,45 & 0,45 & 0,45 & 0,45 & 0,45 \\
\hline $\begin{array}{l}\text { Sal comum } \\
\text { Salt }\end{array}$ & 0,29 & 0,29 & 0,29 & 0,29 & 0,29 \\
\hline $\begin{array}{l}\text { Total } \\
\text { Total }\end{array}$ & 100 & 100 & 100 & 100 & 100 \\
\hline $\begin{array}{l}\text { Matéria seca (\%) } \\
\text { Dry matter (\%) }\end{array}$ & 87,72 & 88,33 & 88,91 & 89,56 & 90,01 \\
\hline $\begin{array}{l}\text { Proteína bruta }(\%) \\
\text { Crude protein }(\%)\end{array}$ & 13,50 & 13,50 & 13,50 & 13,50 & 13,50 \\
\hline $\begin{array}{l}\text { Proteína degrad. rúmen }{ }^{1}(\%) \\
\text { Ruminal degradable protein }\end{array}$ & 7,01 & 7,73 & 8,45 & 9,04 & 9,38 \\
\hline $\begin{array}{l}\text { Proteína não-degradavel rúmen }{ }^{1}(\%) \\
\text { Ruminal undegradable protein }{ }^{1}(\%)\end{array}$ & 6,49 & 5,77 & 5,05 & 4,46 & 4,12 \\
\hline $\begin{array}{l}\text { NDT }(\%) \\
T D N(\%)\end{array}$ & 76,70 & 76,70 & 76,70 & 76,70 & 76,70 \\
\hline $\begin{array}{l}\mathrm{ELm}(\mathrm{kcal} / \mathrm{kg}) \\
N E m(\mathrm{kcal} / \mathrm{kg})\end{array}$ & 1.828 & 1.831 & 1.834 & 1.836 & 1.837 \\
\hline $\begin{array}{l}\mathrm{ELg}(\mathrm{kcal} / \mathrm{kg}) \\
\mathrm{NEg}(\mathrm{kcal} / \mathrm{kg})\end{array}$ & 1.194 & 1.196 & 1.199 & 1.201 & 1.201 \\
\hline $\begin{array}{l}\mathrm{FDN}(\%) \\
N D F(\%)\end{array}$ & 16,00 & 14,74 & 13,49 & 12,48 & 12,31 \\
\hline $\begin{array}{l}\text { Cálcio }^{2}(\%) \\
\text { Calcium }^{2}(\%)\end{array}$ & 0,92 & 0,92 & 0,92 & 0,92 & 0,92 \\
\hline $\begin{array}{l}\text { Fósforo }{ }^{2}(\%) \\
\text { Phosphorus }^{2}(\%)\end{array}$ & 0,58 & 0,58 & 0,58 & 0,58 & 0,58 \\
\hline
\end{tabular}

${ }^{1}$ Segundo dados do NRC (1988).

2 Teores da suplementação mineral.

${ }^{1}$ According to data from NRC (1988).

${ }^{2}$ Levels from mineral supplementation.

do seu nascimento até sete dias de idade. Ao chegarem à propriedade, ficaram privados de leite durante as primeiras 12 horas, recebendo apenas soro por via oral, preparado segundo recomendações da Embrapa - CNPGL (Campos \& Lizieire, 2000), consistindo da mistura de $45 \mathrm{~g}$ de sal e $250 \mathrm{~g}$ de açúcar, para cada
5 litros de água. A partir daí, o manejo foi idêntico ao dos animais nascidos na propriedade.

Todos os animais foram avaliados qualitativamente quanto à concentração de imunoglobulinas no sangue, segundo as recomendações de Charles et al. (1994).

O critério para desaleitamento dos animais foi o 
consumo de concentrado, sendo que, quando estavam consumindo ao redor de $800 \mathrm{~g}$ por dia, estes tiveram o fornecimento de leite cessado de uma vez, passando a consumir apenas o concentrado experimental. Uma semana antes do desaleitamento, foi ocorrendo a substituição gradativa do concentrado comercial pelos concentrados experimentais.

O desaleitamento foi realizado em três datas diferentes, sendo a primeira em 18/06/1999 (18 animais), seguido por outro em 10/07 (12 animais) e, por fim, em 22/07 (5 animais). Os animais foram sorteados aleatoriamente entre os cinco tratamentos

Os animais foram vacinados contra aftosa, pneumoenterite e salmonelose e receberam dosagens de vitamina A e D, conforme NRC (1988). Foram submetidos a um controle sistemático de ecto e endo parasitas. Os bezerreiros foram limpos diariamente e mudados de local a cada vinte dias. Os animais foram presos por correntes, para impedir o contato direto entre os mesmos. Os recipientes utilizados para fornecimento de leite foram higienizados, após cada aleitamento e os baldes para o fornecimento de água, diariamente.

Os animais foram pesados, em balança eletrônica com $0,5 \mathrm{~kg}$ de precisão, logo ao nascimento ou após a chegada na propriedade e, posteriormente, a cada sete dias, até ao desaleitamento, quando também ocorreu nova pesagem. Posteriormente, foram feitas pesagens a cada 28 dias, para obtenção do ganho médio diário, totalizando três períodos em 84 dias de experimento. As pesagens foram após 15 horas de jejum, pela manhã, às $8 \mathrm{~h}$. Foram realizadas anotações diárias da quantidade de concentrado fornecido e das sobras, para cada animal, para determinar o consumo total de matéria seca e conversão alimentar.

Foram realizadas amostragens semanais dos concentrados, do feno fornecido e das sobras. Após a amostragem, o material foi acondicionado em sacos plásticos, devidamente identificados e guardados em freezer $\left(-10^{\circ} \mathrm{C}\right)$, para posterior análise.

Foram colhidas amostras de sangue dos animais em tubos com vácuo, contendo heparina sódica, por ocasião do desaleitamento e do final ao experimento. Foi determinada a porcentagem de hematócritos das amostras, que posteriormente foram centrifugadas, sendo o plasma congelado $\left(-20^{\circ} \mathrm{C}\right)$, para posteriores análises de glicose e uréia.
As coletas de sangue foram no período da tarde, sendo acondicionadas em caixa térmica contendo gelo e processadas, logo a seguir.

Foram realizadas análises dos concentrados fornecidos, das sobras e do feno, para determinação de matéria seca (MS), proteína bruta $(\mathrm{PB})$, energia bruta (EB), fibra em detergente neutro (FDN), extrato etéreo (EE) e fibra bruta (FB) segundo Silva (1990). Para determinação do amido, foi utilizado o método enzimático descrito por Poore et al. (1989), adaptado por Pereira \& Rossi Jr. (1995).

A determinação dos teores de nutrientes digestíveis totais (NDT) para farinha de varredura, milho, farelo de soja e feno de tifton baseou-se na composição química dos alimentos, utilizando a equação para alimentos energéticos, segundo Kearl (1982).

$\% \mathrm{NDT}=40,2625+0,1969 \% \mathrm{~PB}+0,4228 \% \mathrm{ENN}$ $+1,1903 \mathrm{EE} \%-0,1379 \% \mathrm{FB}$

Os valores de energia metabolizável (EM), energia líquida de mantença (ELm) e energia líquida de ganho (ELg) foram calculados conforme recomendações de Sniffen et al. (1992).

$$
\mathrm{EM}=0,82 \times \mathrm{ED}
$$

$\mathrm{ELm}=-1,12+1,37 \times \mathrm{EM}-0,138 \times \mathrm{ME} 2+0,0105 \times \mathrm{EM} 3$ $\mathrm{ELg}=-1,65+1,42 \times \mathrm{EM}-0,174 \times \mathrm{EM} 2+0,0122 \times \mathrm{ME} 3$

O delineamento experimental foi inteiramente casualizado, com cinco tratamentos $(0,25,50,75 \mathrm{e}$ $100 \%$ de substituição do milho pela farinha de varredura de mandioca) e sete repetições. As análises estatísticas das variáveis estudadas (consumo, ganho médio diário, conversão alimentar e níveis de hematócrito, glicose e uréia sangüíneos) foram interpretadas por análises de variância e regressão, utilizando o Sistema de Análises Estatísticas e Genéticas - SAEG (UFV, 1983), de acordo com o seguinte modelo:

$$
\mathrm{Y}_{\mathrm{ij}}=\mu+\mathrm{N}_{\mathrm{i}}+\mathrm{b}_{1}(\mathrm{PI}-\mathrm{PM})+\mathrm{e}_{\mathrm{ij}}
$$

em que: $Y_{i j k}=$ valor observado da variável estudada no indivíduo $\mathrm{j}$, recebendo a ração com nível i de substituição do milho pela farinha de varredura; $\mu=$ constante geral da variável; $\mathrm{N}_{\mathrm{i}}=$ efeito do nível $\mathrm{i}$ de substituição do milho pela farinha de varredura $(i=0,25,50,75$ e 100); b1 = coeficiente linear de regressão de $\mathrm{Y}$, em função do peso inicial (PI); $\mathrm{PI}=$ peso inicial ao desaleitamento; $\mathrm{PM}=$ peso inicial médio; $\mathrm{e}_{\mathrm{ij}}=$ erro aleatório associado a cada observação $\mathrm{Y}_{\mathrm{ij}}$.

Os graus de liberdade para níveis de substituição do milho pela farinha de varredura de mandioca foram desdobrados em polinômios ortogonais. 


\section{Resultados e Discussão}

Os dados do consumo de matéria seca e de nutrientes serão expressos somente em relação ao consumo de concentrado dos animais (Tabela 4). Houve fornecimento diário de feno de Tifton 85 para os animais, porém, as dificuldades de manejo e mensuração do fornecido e das sobras deste volumoso, nas condições em que o experimento foi realizado, tornaram difíceis as estimativas de consumo de feno, sendo estas feitas apenas por observações visuais, sem mensurações. $\mathrm{O}$ consumo deste, no período pré e pós-desaleitamento, foi baixo, podendo o fornecimento de concentrado à vontade, durante parte do experimento, ter contribuído para o baixo consumo de feno, como visualizado durante a condução do experimento. O consumo de matéria seca do concentrado expresso em porcentagem do peso vivo indica o alto consumo de concentrado, em relação à dieta total (Tabela 4).
A elevação dos níveis de substituição do milho pela farinha de varredura na dieta proporcionou comportamento linear decrescente para o consumo médio total de matéria seca, com valores estimados, variando de 2,93 a $2,58 \mathrm{~kg} / \mathrm{dia}$. O mesmo comportamento ocorreu no primeiro e segundo períodos de 28 dias (2,24 a 1,70 e 3,04 a 2,42 kg MS/dia, respectivamente). No terceiro e último períodos de 28 dias, o consumo foi limitado a $3,56 \mathrm{~kg} \mathrm{MS} /$ dia, sendo que todos os animais atingiram este consumo no início do período, mantendo o mesmo até o final.

O consumo de matéria seca, em relação ao peso vivo dos animais, comportou-se da mesma forma, com resposta linear decrescente para o aumento dos níveis de substituição ( 2,40 a 2,18\% do peso vivo).

Houve redução linear para o consumo de proteína bruta, devido à redução no consumo de MS, com valores estimados, pela equação de regressão, variando de 0,42 a $0,36 \mathrm{~kg} / \mathrm{dia}$. Da mesma forma, houve

Tabela 4 - Médias, equações de regressão ajustadas (ER) e coeficientes de variação (CV) para o consumo de nutrientes para as dietas experimentais

Table 4 - Means, fitted regression equations (RE) and coefficients of variation (CV) for the nutrients intake of the experimental diets

\begin{tabular}{|c|c|c|c|c|c|c|c|}
\hline \multirow[t]{2}{*}{ Item } & \multicolumn{5}{|c|}{$\begin{array}{c}\text { Nível de substituição (\%) } \\
\text { Replacement level (\%) }\end{array}$} & \multirow[t]{2}{*}{$\mathrm{CV}(\%)$} & \multirow[t]{2}{*}{$\begin{array}{l}\mathrm{ER} \\
R E\end{array}$} \\
\hline & 0 & 25 & 50 & 75 & 100 & & \\
\hline $\begin{array}{l}\text { CTMS (kg/dia) } \\
\text { TDMI (kg/day) }\end{array}$ & 2,90 & 2,91 & 2,73 & 2,64 & 2,59 & 8,6 & 1 \\
\hline $\begin{array}{l}\text { CTMS }(\% \mathrm{PV} / \text { dia }) \\
\text { TDMI (\%LW/day })\end{array}$ & 2,43 & 2,35 & 2,26 & 2,18 & 2,23 & 7,1 & 2 \\
\hline $\begin{array}{l}\text { CMSP1 (kg/dia) } \\
P 1 D M I(\mathrm{~kg} / \text { day })\end{array}$ & 2,26 & 2,13 & 1,90 & 1,82 & 1,74 & 14,5 & 3 \\
\hline $\begin{array}{l}\text { CMSP2 (kg/dia }) \\
P 2 D M I(k g / d a y)\end{array}$ & 2,93 & 3,07 & 2,72 & 2,51 & 2,43 & 18,1 & 4 \\
\hline $\begin{array}{l}\text { CMSP3 (kg/dia) } \\
\text { P3DMI (kg/day) }\end{array}$ & 3,56 & 3,56 & 3,56 & 3,56 & 3,56 & 0,0 & $Y=3,56$ \\
\hline $\begin{array}{l}\text { CPB }(\mathrm{kg} / \mathrm{dia}) \\
C P I(\mathrm{~kg} / \text { day })\end{array}$ & 0,41 & 0,41 & 0,39 & 0,37 & 0,36 & 8,7 & 5 \\
\hline $\begin{array}{l}\text { CFDN (kg/dia) } \\
\text { NDFI (kg/day) }\end{array}$ & 0,46 & 0,43 & 0,37 & 0,33 & 0,31 & 8,6 & 6 \\
\hline $\begin{array}{l}\text { CAMIDO (kg/dia) } \\
\text { STRCHI (kg/day) }\end{array}$ & 1,69 & 1,76 & 1,72 & 1,70 & 1,68 & 8,6 & $\mathrm{Y}=1,71$ \\
\hline $\begin{array}{l}\text { 1. } \mathrm{Y}=2,927-0,00351^{* *} \mathrm{~N} \\
\text { 2. } \mathrm{Y}=2,402-0,0022^{* *} \mathrm{~N} \\
\text { 3. } \mathrm{Y}=2,236-0,00534^{* *} \mathrm{~N} \\
\text { 4. } \mathrm{Y}=3,035-0,00611^{*} \mathrm{~N} \\
\text { 5. } \mathrm{Y}=0,416-0,00056^{* *} \mathrm{~N} \\
6 . \mathrm{Y}=0,460-0,00159^{* *} \mathrm{~N}\end{array}$ & & & & & & & $\begin{aligned} \mathrm{r}^{2} & =0,92 \\
\mathrm{r}^{2} & =0,81 \\
\mathrm{r}^{2} & =0,96 \\
\mathrm{r}^{2} & =0,83 \\
\mathrm{r}^{2} & =0,93 \\
\mathrm{r}^{2} & =0,97\end{aligned}$ \\
\hline $\begin{array}{l}\left.{ }^{*} \mathrm{P}<0,05\right) \text { e }{ }^{* *}(\mathrm{P}<0,01) . \\
\mathrm{N}=\text { Nível de substituição }(\%) \\
\mathrm{CTMS}=\text { consumo total médio } \\
\text { de } 28 \text { dias, respectivamente; } \\
N=\text { Level of substitution }(\%) . \\
\text { TDMI = total dry matterintake; } P 1 L\end{array}$ & $\begin{array}{l}\text { téria s } \\
\text { consu }\end{array}$ & dryme & $\begin{array}{l}\text { CMSF } \\
\text { FDN }= \\
\text { forthe }\end{array}$ & $\begin{array}{l}\text { mo de } \\
\text { de fibr }\end{array}$ & $\begin{array}{l}\text { seca } \\
\text { tergei }\end{array}$ & $\begin{array}{l}\text { iro, segun } \\
\text { e Camide } \\
\text { tein intake; }\end{array}$ & $\begin{array}{l}\text { eiro período } \\
\text { umo de amid }\end{array}$ \\
\hline
\end{tabular}


redução linear no consumo de $\mathrm{FDN}(0,46$ a $0,30 \mathrm{~kg} / \mathrm{dia})$. $O$ consumo de amido não foi influenciado pelas rações $(1,71 \mathrm{~kg} / \mathrm{dia})$.

O apetite é regulado por mecanismos quimiostáticos e limitações físicas do aparelho digestivo (Van Soest, 1994). Fatores físicos são importantes na limitação do consumo voluntário. Estes fatores agem por limites impostos na capacidade do retículo e rúmen e pelo tempo de permanência do alimento no órgão. Em dietas de altas digestibilidades, como no caso de dietas com altos níveis de concentrado, que não levariam a um completo enchimento do rúmen, seria pouco provável que os fatores físicos limitassem o consumo voluntário das rações experimentais, à medida em que se elevassem os níveis de farinha de varredura.

Segundo Hill (1970), citado por Peixoto \& Warner (1993) e Van Soest (1994), o alimento ao entrar na boca, estimula a secreção de saliva, que é atribuída ao estímulo reflexo das glândulas salivares, por intermédio dos receptores bucais. Em geral, alimentos tradicionais utilizados na alimentação animal causam secreção de saliva rica em mucina e enzimas, o que facilita a deglutição, enquanto alimentos muito secos provocam considerável fluxo de saliva aquosa, com muito pouca mucina. Mastigação prolongada conduz à maior secreção salivar por meio de estímulo prolongado dos terminais na boca. A saliva é importante, porque sua função lubrificante facilita a mastigação e a deglutição do alimento ingerido. O conteúdo de mucina é particularmente útil por ajudar a formar adequadamente o bolo alimentar apropriado ao ato de deglutir.

A farinha de varredura é seca $(90 \%$ de matéria seca ou mais) e com textura de pó, de maneira que os bezerros não mastigam como fazem com o milho moído grosseiramente. Como consequência, menos saliva com alto teor de mucina é secretada, acarretando prejuízo na deglutição, provavelmente, levando a desencorajamento para elevar o consumo. Outro fato que pode prejudicar o consumo da farinha de varredura é o baixo teor de extrato etéreo na sua composição (menos de $1 \%$ ), pois a gordura do alimento confere gosto e sabor.

Peixoto \& Warner (1993), em um experimento utilizando 64 bezerros holandeses, desmamados na sexta semana de vida, utilizando rações com $50 \%$ de milho e substituições de 50 e $100 \%$ por farinha de mandioca, também observaram diminuição no consumo de ração $(\mathrm{P}<0,05)$ para o tratamento com $100 \%$ de substituição $\left(79,43 \mathrm{~kg}\right.$ de ração da $6^{\mathrm{a}}$ a $16^{\mathrm{a}}$ semana de vida), sendo que o tratamento com milho e $50 \%$ de substituição não diferiu $(\mathrm{P}>0,05)$ no consumo de ração $\left(105,67\right.$ e $103,90 \mathrm{~kg}$ da $6^{\mathrm{a}}$ a $16^{\mathrm{a}}$ semanas, respectivamente). Concluíram, ainda, que bezerros desaleitados precocemente e submetidos a elevados fornecimentos de farinha de mandioca ( $50 \%$ na composição da ração - $100 \%$ de substituição ao milho) têm o consumo de ração diminuído, o que, da mesma forma, foi observado no presente experimento. Marques et al. (2000) também verificaram redução de consumo de MS $(\mathrm{P}<0,05)$, de 11,5 para $8,3 \mathrm{~kg} / \mathrm{dia}$, ao fornecerem dietas com silagem de milho, farelo de soja e farinha de varredura em substituição total ao milho, no desempenho de novilhas com 24 meses de idade e peso médio de $365 \mathrm{~kg}$.

Consumos médios de matéria seca (MS) superiores aos observados no presente experimento foram encontrados por Araújo et al. (1998) e Signoretti et al. (1998), ao fornecerem a bezerros holandeses desaleitados, dos 60 até 180 dias de idade, níveis de volumoso (feno de tifton), variando de 10 a 55\% na dieta. Esses autores observaram que o consumo de MS variou de 3,45 a 4,01 kg/dia. Todavia, vale ressaltar que, para a determinação do consumo médio de MS observado no presente trabalho, que variou de 2,93 a $2,58 \mathrm{~kg} / \mathrm{dia}$, foram considerados somente dados do concentrado, sendo que, no último período de 28 dias, este foi limitado para favorecer a ingestão de feno. Por outro lado, os consumos obtidos por Salles \& Lucci (1998), ao testar níveis de monensina sódica no crescimento de 20 bezerros holandeses, com 83 dias de idade e alimentados com $20 \%$ de feno de coastcross e concentrado, também foram maiores, variando de 4,19 a 5,03 kg/dia.

Em um sistema de produção testado pela Embrapa Gado de Leite, para o abate precoce de bezerros holandeses ao redor de $200 \mathrm{~kg}$, citado em Campos \& Lizieire (2000), foram utilizados concentrados cuja composição bromatológica foi semelhante à adotada neste experimento e oferecidos desde a segunda semana de idade, sempre à vontade, aos animais. Os bezerros holandeses consumiram, em média, $3,3 \mathrm{~kg} /$ animal/dia, dos 71 a 120 dias de idade e $5,4 \mathrm{~kg} /$ animal/ dia, dos 121 aos 182 dias. Vale ressaltar que, neste sistema, não foi utilizado volumoso e, no período total (do nascimento ao abate), foram gastos $550 \mathrm{~kg}$ de concentrado, por bezerro. O consumo para o nível de $0 \%$ de substituição (100\% milho) foi próximo ao observado, cujo concentrado foi semelhante ao utilizado por Campos \& Lizieire (2000).

O menor consumo de MS registrado neste expe- 
rimento está correlacionado, principalmente, à limitação do fornecimento de concentrado no período final, para estimular o consumo de volumoso, e, também, à falta de dados sobre o consumo de feno.

As médias e coeficientes de variação para idade e peso ao desaleitamento e no final do experimento, valores observados, equações de regressão ajustadas (ER) e coeficientes de variação (CV), para ganho médio diário total (GMD), ganho médio diário para os períodos 1 (GDP1), 2 (GDP2) e 3 (GDP3) e conversão alimentar da matéria seca (CAMS), em função dos níveis de substituição de milho pela farinha de varredura, são mostrados na Tabela 5 .

Os animais foram desaleitados com idades médias variando de 77 a 81 dias de idade. Apresentaram peso ao desaleitamento, variando de 78,0 a $81,6 \mathrm{~kg}$ de peso vivo. No período que precedeu ao desaleitamento, o ganho médio diário dos animais foi de $0,67 \mathrm{~kg} / \mathrm{dia}$. Este ganho foi satisfatório, pois, segundo Campos \& Lizieire (2000), para a produção do bezerrão, tem sido recomendado um ganho de 0,45 a $0,50 \mathrm{~kg} /$ dia do nascimento aos 60 dias de idade. Houve redução linear para o ganho médio diário, à medida em que se aumentaram os níveis de substituição (1,03 a $0,90 \mathrm{~kg} / \mathrm{dia})$. O mesmo comportamento foi observado para o GDP $1(0,93$ a $0,68 \mathrm{~kg} / \mathrm{dia})$ e para o GDP2 $(1,10$ a $0,89 \mathrm{~kg} / \mathrm{dia})$. No último período (GDP3), não houve efeito dos níveis de substituição do milho pela FV $(\mathrm{P}>0,05)$ sobre o ganho de peso vivo $(1,09 \mathrm{~kg} / \mathrm{dia})$.

A redução do GMD dos animais, à medida em que se aumentou a inclusão de farinha de varredura nas dietas, foi causada pela diminuição ocorrida no CTMS, acarretando menores disponibilidades de nutrientes para os animais com maiores níveis de substituição. Isto pode ser visto na ingestão de proteína bruta (IPB), que decaiu linearmente com o aumento dos níveis. Essa menor quantidade de nutrientes ingerida deve ter limitado o ganho de peso, pela menor disponibilidade destes para a utilização no crescimento. Outro fator pode ter sido a diminuição gradativa da

Tabela 5 - Médias e coeficientes de variação (CV) para idade e pesos ao desaleitamento e ao final do experimento, valores observados e equações de regressão ajustadas (ER) para o ganho de peso e conversão alimentar

Table 5 - Means and coefficient of variation (CV) for age and weight at weaning and the end of experiment, observed values and fitted regression equations (RE) for weight gain and feed:gain ratio

\begin{tabular}{|c|c|c|c|c|c|c|c|}
\hline \multirow[t]{2}{*}{ Item } & \multicolumn{5}{|c|}{$\begin{array}{l}\text { Nível de substituição (\%) } \\
\text { Replacement level (\%) }\end{array}$} & \multirow[t]{2}{*}{$\mathrm{CV}(\%)$} & \multirow[t]{2}{*}{$\begin{array}{l}\mathrm{ER} \\
R E\end{array}$} \\
\hline & 0 & 25 & 50 & 75 & 100 & & \\
\hline $\begin{array}{l}\text { Idade ao desaleitamento (dias) } \\
\text { Weaning age (days) }\end{array}$ & 79 & 81 & 77 & 80 & 81 & 15,3 & - \\
\hline $\begin{array}{l}\text { Peso ao desaleitamento }(\mathrm{kg}) \\
\text { Weaning weight }(\mathrm{kg})\end{array}$ & 78,0 & 81,0 & 81,6 & 79,3 & 80,1 & 11,2 & - \\
\hline $\begin{array}{l}\text { Peso final }(\mathrm{kg}) \\
\text { Final weight }(\mathrm{kg})\end{array}$ & 163,4 & 167,2 & 160,3 & 162,2 & 151,9 & 5,1 & - \\
\hline $\begin{array}{l}\text { Idade final (dias) } \\
\text { Final age (days) }\end{array}$ & 163 & 165 & 161 & 164 & 165 & 15,3 & - \\
\hline $\begin{array}{l}\mathrm{GMD}(\mathrm{kg} / \mathrm{dia}) \\
A D G(\mathrm{~kg} / \text { dia })\end{array}$ & 1,00 & 1,03 & 0,94 & 0,99 & 0,86 & 10,2 & 1 \\
\hline $\begin{array}{l}\text { GDP1(kg/dia }) \\
P 1 A D G(\mathrm{~kg} / \text { day })\end{array}$ & 0,94 & 0,86 & 0,80 & 0,76 & 0,67 & 21,7 & 2 \\
\hline $\begin{array}{l}\mathrm{GDP} 2(\mathrm{~kg} / \mathrm{dia}) \\
P 2 A D G(\mathrm{~kg} / \text { day })\end{array}$ & 1,07 & 1,08 & 0,94 & 1,04 & 0,83 & 15,4 & 3 \\
\hline $\begin{array}{l}G D P 3(\mathrm{~kg} / \mathrm{dia}) \\
P 3 A G D(\mathrm{~kg} / \text { day })\end{array}$ & 0,99 & 1,14 & 1,07 & 1,17 & 1,06 & 18,8 & $\mathrm{Y}=1,09$ \\
\hline $\begin{array}{l}\text { CAMS (kg/kg ganho) } \\
F G R D M(\mathrm{~kg} / \mathrm{kg} \text { gain })\end{array}$ & 2,9 & 2,9 & 2,9 & 2,7 & 3,0 & 9,7 & $\mathrm{Y}=2,9$ \\
\hline $\begin{array}{l}\text { 1. } \mathrm{Y}=1,027-0,00131^{* *} \mathrm{~N} \\
\text { 2. } \mathrm{Y}=0,934-0,00254^{* *} \mathrm{~N} \\
\text { 3. } \mathrm{Y}=1,095-0,00204^{* *} \mathrm{~N}\end{array}$ & & & & & & & $\begin{array}{l}r^{2}=0,60 \\
r^{2}=0,99 \\
r^{2}=0,61\end{array}$ \\
\hline $\begin{array}{l}\text { ** }(\mathrm{P}<0,01) \\
\mathrm{N}=\text { nível de substituição }(\%) . \\
\mathrm{GMD}=\text { ganho médio diário total; GDP1 } \\
\mathrm{CAMS}=\text { conversão alimentar da ma } \\
N=\text { replacement level (\%). } \\
A D G=\text { average daily gain; P1ADG, P2A } \\
\text { of dry matter. }\end{array}$ & $\begin{array}{l}\text { eGD } \\
\text { Ca. }\end{array}$ & hom & para & , seg & ercei & de 28 & ectivamente \\
\hline
\end{tabular}

R. Bras. Zootec., v.31, n.1, p.192-204, 2002 
qualidade da proteína fornecida, com a utilização em níveis crescente de nitrogênio não protéico (uréia), com o fornecimento da farinha de varredura na formulação das dietas. Todavia, os níveis de uréia fornecidos estavam dentro dos limites recomendados pelo NRC (1988), para bezerros holandeses.

Pode-se confirmar o menor consumo como causador da diminuição no ganho de peso, ao se avaliar este nos três períodos, separadamente, observando-se a mudança de tendência no comportamento das retas obtidas por intermédio das equações de regressão (Figura 1). No período 1, logo após o desaleitamento, o estresse da mudança de alimentação líquida para a sólida, além da substituição do milho no concentrado comercial, utilizado no período pré-desaleitamento, pela farinha de varredura nas rações experimentais, um alimento mais seco e pulverulento que o milho, reduziram o consumo do concentrado. No segundo período, quando os animais estavam mais adaptados à consistência da farinha de varredura, pode-se observar diminuição na diferença entre os ganhos de peso e entre os níveis de substituição. No período 1, a diferença entre o ganho médio diário do nível zero para o de $100 \%$ de substituição, foi $27 \%$ menor para o nível $100 \%$. No período 2 , essa diferença foi de $18,6 \%$. Isto pode indicar adaptação dos animais ao alimento e, também, possivelmente, ganho compensatório. Destaca-se a avaliação do período 3, no qual os consumos de matéria seca foram semelhantes entre os níveis, pela limitação das

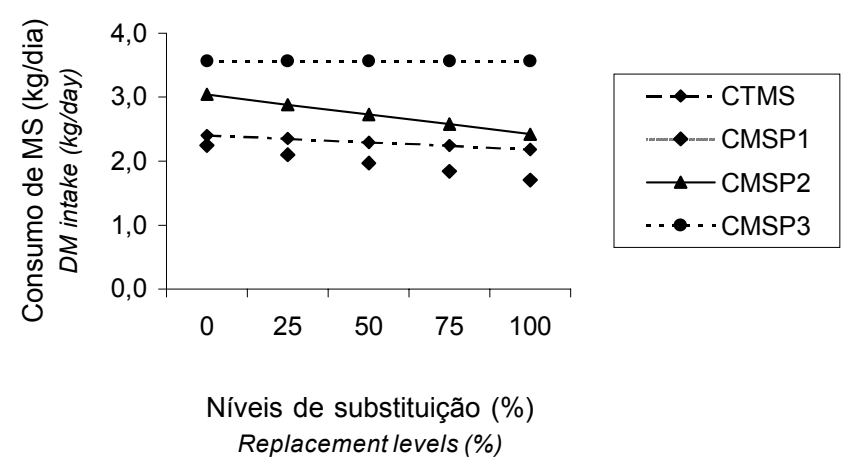

Figura 1 - Consumo médio total de matéria seca (CTMS) e consumos médios de matéria seca no primeiro, segundo e terceiro períodos de 28 dias (CMSP1, CMSP2 e CMSP3, respectivamente), em função dos níveis de substituição.

Figure 1 - Total dry matter intake and dry matter intakes for the first, second, and third periods of 28 days, in function of the replacement levels. dietas fornecidas. Com consumos semelhantes de matéria seca, não foi encontrada diferença entre os níveis de substituição, para o ganho de peso, estimado em 1,09 $\mathrm{kg} /$ dia para todos os animais. Esta mudança de comportamento pode ser observada na Figura 2.

A CAMS não diferiu para nenhum dos níveis, apresentando valor estimado de $2,9 \mathrm{~kg} / \mathrm{kg}$ e o mesmo foi observado nos três períodos. Vale ressaltar que, para o consumo de MS, foi computado apenas o concentrado. Isto confirma o CMS como fator determinante no GMD. Estes resultados estão em acordo com aqueles obtidos por Peixoto \& Warner (1993), que encontraram diferenças para o consumo das rações e para ganho de peso, mas não para a conversão alimentar e concluíram que a diminuição no desenvolvimento dos animais foi devido ao menor consumo e não à menor eficiência na utilização das dietas, à base de farinha de mandioca.

Apesar da diminuição do ganho de peso com o incremento dos níveis de substituição da FV, o GMD obtido para o nível 100\% pode ser considerado satisfatório (0,90 kg /dia). Este valor é intermediário ao encontrado em vários trabalhos na literatura. Lucci et al. (1974), citados por Lucci (1989), num experimento com 24 bezerros holandeses, conduzidos dos 91 aos 180 dias de idade, recebendo mistura concentrada com teor protéico de $20 \%$ mais feno de capim-gordura de baixa qualidade, à vontade, verificaram ganho diário de $0,70 \mathrm{~kg} /$ dia, atingindo-se 143

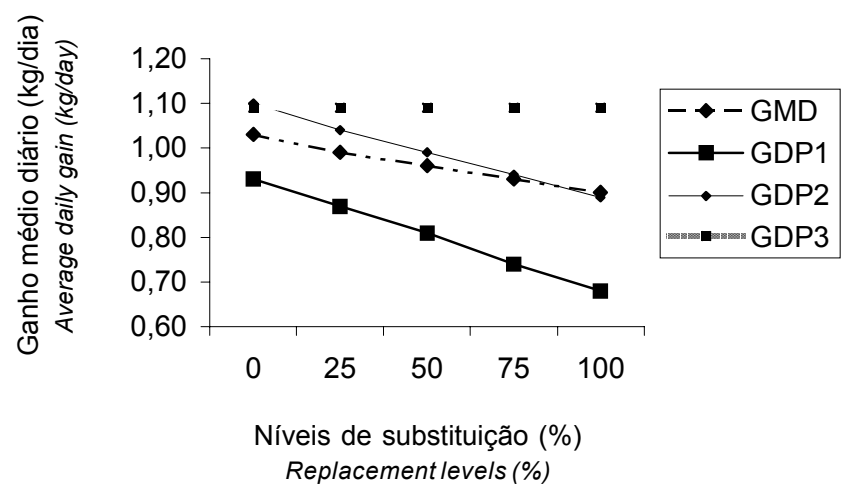

Figura 2 - Ganho médio diário total (GMD) e ganhos médios diários para o primeiro, segundo e terceiro períodos de 28 dias (GDP1, GDP2 e GDP3, respectivamente), em função dos níveis de substituição.

Figure 2 - Mean weight gain and average daily weight gain for the first, second and third periods of 28 days, in function of the replacement levels. 
kg aos 180 dias. Araújo et al. (1998), estudando níveis de volumoso na dieta de 10 a 55\%, para animais de 60 a 180 dias de idade, obtiveram valores médios, variando de 1,01 a 0,71 kg/dia. Neste mesmo trabalho, o GMD para os primeiros 28 dias pós desaleitamento, variou de 0,94 a $0,66 \mathrm{~kg} / \mathrm{dia}$, de $0,82 \mathrm{~kg} /$ dia para $\mathrm{o}$ segundo período e $0,81 \mathrm{~kg} /$ dia para o terceiro. Estes autores ainda concluíram que o ganho médio geral de peso vivo, obtido no experimento $(0,87 \mathrm{~kg} / \mathrm{dia})$, foi bom. Signoretti et al. (1998) obtiveram valores de ganho de peso variando de 1,23 a 0,92 kg/dia. Salles \& Lucci (1998) encontraram valores de ganho de peso superior aos do presente experimento, variando de 1,06 a $1,37 \mathrm{~kg} /$ dia, nos diferentes níveis de inclusão de monensina sódica em bezerros holandeses desaleitados precocemente.

As recomendações da Embrapa (Campos \& Lizieire, 2000) para a produção do bezerrão são que os animais atinjam ganho entre 0,90 e $1,00 \mathrm{~kg} / \mathrm{dia}$, na fase entre 60 a 120 dias de idade e de 1,20 a $1,30 \mathrm{~kg} /$ dia, de 121 a 180 dias de idade. Ainda relataram resultados em que os animais apresentaram ganhos médios diários de $0,45 \mathrm{~kg}$, do nascimento aos 70 dias de idade, $0,99 \mathrm{~kg}$ dos 71 aos 120 dias de idade, e $1,20 \mathrm{~kg}$ dos 121 aos 182 dias de idade, quando foram abatidos, em média, com $196 \mathrm{~kg}$ de peso vivo. Os ganhos de $0,67 \mathrm{~kg} /$ dia na fase pré experimental, e de 0,93 e $1,10 \mathrm{~kg} /$ dia para o nível $0 \%$ para os períodos 1 e 2, estão em acordo com os dados e recomendações da Embrapa. O ganho de peso dos animais do período 3 foi baixo, o que foi devido à limitação no fornecimento de concentrado para os animais, não permitindo, assim, a expressão de maiores ganhos.

Com base na literatura citada, os ganhos de peso obtidos para todos os níveis de substituição do milho pela farinha de varredura podem ser considerados satisfatórios. O que determinará o nível a ser utilizado dependerá dos preços de mercado do milho e da disponibilidade da farinha de varredura, que é um resíduo industrial e não está disponível em todas as regiões, muitas vezes, não sendo encontrada em quantidades significativas. Outro fator a ser considerado é o planejamento do ganho de peso dos animais e, a partir de ganhos alvo, escolher o melhor nível ou a melhor época de utilização, pois é necessário uma adaptação por parte dos animais ao consumo da farinha. O aumento gradativo dos níveis de inclusão de farinha de varredura, logo após ao desaleitamento, também é uma alternativa viável, começando com níveis menores. À medida que o consumo se estabi- lizar, pode-se aumentar gradativamente a inclusão, até ao nível de substituição total, quando não houver mais o problema ocasionado pelo consumo.

Os valores observados de hematócrito, glicose e uréia sangüínea para o período do desaleitamento ( 80 dias de idade) e final do experimento (164 dias de idade), coeficientes de variação e equações de regressão estão descritos na Tabela 6 .

Os valores de hematócrito, glicose e uréia sangüíneos não diferiram no período do desaleitamento e no período relativo ao final do experimento. A inclusão de farinha de varredura não influenciou os parâmetros sangüíneos estudados.

Verifica-se que os valores obtidos para os parâmetros sangüíneos, com relação à época da colheita, foram maiores $(\mathrm{P}<0,01)$ na desmama que no final do experimento, tanto para hematócrito $(30,7 \mathrm{e}$ $26,0 \%)$, para glicose $(93,2$ e $82,6 \mathrm{mg} / 100 \mathrm{~mL})$ e para uréia $(22,4$ e $11,2 \mathrm{mg} / 100 \mathrm{~mL})$.

Barnes et al. (1985) encontraram valores de $10,3 \mathrm{mg} / 100 \mathrm{~mL}$ para uréia e $60,6 \mathrm{mg} / 100 \mathrm{~mL}$ para glicose, em bezerras Holandesas, com seis meses de idade e alimentadas com rações com 15,5\% de proteína bruta. Todavia, os valores observados no presente experimento foram superiores aos de Park (1985), que utilizou bezerros holandeses com $100 \mathrm{~kg}$ de peso vivo submetidos a uma dieta com $12 \%$ de proteína bruta e encontrou 8,0 mg de uréia/100 mL e 75,8 mg de glicose/ $100 \mathrm{~mL}$. Diaz-Castaneda \& Brisson (1989) observaram, em bezerros holandeses com aproximadamente 60 dias de idade, alimentados com rações contendo 28,7\% de proteína bruta, níveis de uréia variando de 11 a $18 \mathrm{mg} / 100 \mathrm{~mL}$ e de glicose de 65 a $85 \mathrm{mg} / 100 \mathrm{~mL}$.

Neathery et al. (1991) encontraram valores de $32,4 \%$ de hematócrito e $102 \mathrm{mg}$ de glicose $/ 100 \mathrm{~mL}$ e $11,2 \mathrm{mg}$ uréia/ $100 \mathrm{~mL}$ em bezerros holandeses alimentados com rações com $21,0 \%$ de proteína bruta, com $124 \mathrm{~kg}$ de peso vivo e $1,18 \mathrm{~kg} / \mathrm{dia}$ de ganho de peso.

Os valores observados estão de acordo com Matsuzaki et al. (1997), que determinaram valores de $80 \mathrm{mg}$ glicose $/ 100 \mathrm{~mL}$ e $9 \mathrm{mg}$ uréia/100 mL, em bezerros holandeses com 180 dias de idade e peso vivo de $200 \mathrm{~kg}$, alimentados com concentrado à base de $1 \%$ do peso vivo, com $16,6 \%$ de $\mathrm{PB}$ e $73,0 \%$ de NDT e feno de gramínea.

Os níveis de glicose e uréia sangüíneas são considerados por refletir a quantidade de amido e proteína ingeridos ou a relação entre estes nutrientes consumidos (Blowey et al., 1973; citados por Matsuzaki et al., 1997). Esta afirmação, possivelmen- 
Tabela 6 - Valores observados de hematócrito, glicose e uréia sanguíneo para o período do desaleitamento e final do experimento, coeficientes de variação e equações de regressão

Table 6 - Values of blood hematocrit, glucose and urea at weaning and in the end of experiment, coefficient of variation and fitted regression equations

\begin{tabular}{|c|c|c|c|c|c|c|c|}
\hline \multirow[t]{2}{*}{$\begin{array}{l}\text { Período (dias de idade) } \\
\text { Period (days of age) }\end{array}$} & \multicolumn{5}{|c|}{$\begin{array}{l}\text { Nível de substituição (\%) } \\
\text { Replacement level (\%) }\end{array}$} & \multirow[t]{2}{*}{$\mathrm{CV}(\%)$} & \multirow[t]{2}{*}{$\begin{array}{l}\mathrm{ER} \\
R E\end{array}$} \\
\hline & 0 & 25 & 50 & 75 & 100 & & \\
\hline \multicolumn{8}{|c|}{$\begin{array}{l}\text { Hematócrito }(\%) \\
\text { Hematocrit }\end{array}$} \\
\hline $\begin{array}{l}\text { Desaleitamento ( } 80 \text { dias }) \\
\text { Weaning ( } 80 \text { days })\end{array}$ & 31,9 & 29,6 & 29,9 & 31,7 & 30,5 & 10,5 & $Y=30,7^{a}$ \\
\hline $\begin{array}{l}\text { Final do experimento ( } 164 \text { dias) } \\
\text { End of the experiment (164 days) }\end{array}$ & 25,9 & 27,7 & 27,0 & 25,1 & 24,5 & 12,8 & $Y=26,0^{b}$ \\
\hline \multicolumn{8}{|c|}{$\begin{array}{c}\text { Glicose (mg/100 mL plasma) } \\
\text { Glucose }\end{array}$} \\
\hline $\begin{array}{l}\text { Desaleitamento ( } 80 \text { dias }) \\
\text { Weaning ( } 80 \text { days) }\end{array}$ & 97,9 & 95,9 & 92,3 & 88,0 & 91,9 & 11,6 & $\mathrm{Y}=93,2^{\mathrm{a}}$ \\
\hline $\begin{array}{l}\text { Final do experimento ( } 164 \text { dias) } \\
\text { End of the experiment (164 days) }\end{array}$ & 89,1 & 86,3 & 76,0 & 82,9 & 78,9 & 16,4 & $Y=82,6^{b}$ \\
\hline \multicolumn{8}{|c|}{$\begin{array}{l}\text { Uréia }(\mathrm{mg} / 100 \mathrm{~mL} \text { plasma }) \\
\text { Urea }\end{array}$} \\
\hline $\begin{array}{l}\text { Desaleitamento ( } 80 \text { dias }) \\
\text { Weaning ( } 80 \text { days })\end{array}$ & 21,0 & 17,4 & 29,7 & 20,7 & 23,0 & 58,7 & $Y=22,4^{a}$ \\
\hline $\begin{array}{l}\text { Final do experimento ( } 164 \text { dias) } \\
\text { End of the experiment (164 days) }\end{array}$ & 11,1 & 9,7 & 11,4 & 8,4 & 15,1 & 66,5 & $Y=11,2^{b}$ \\
\hline
\end{tabular}

Médias nas mesmas colunas para cada parâmetro, seguidas de letras diferentes diferem $(P<0,01)$ pelo teste Tukey.

Means in the same collums for each parameter, followed by different letters, differ $(P<.01)$ by Tukey test.

te, explica a não influência dos níveis de substituição da $\mathrm{FV}$, nos teores de glicose e uréia sanguíneos, pois o consumo de amido não diferiu entre os tratamentos.

A diminuição nos níveis de uréia do desaleitamento para o período do final do experimento pode ter sido relacionada com os níveis protéicos a que os animais estavam submetidos, pois, até o desaleitamento, estes receberam concentrado comercial com $20,7 \%$ de proteína bruta, enquanto, no período final do experimento, o concentrado continha $13,5 \%$ (Tabela 3 ).

\section{Conclusões}

A substituição do milho pela farinha de varredura reduziu o consumo de matéria seca, proteína bruta e fibra em detergente neutro, mas não o consumo de amido. O ganho de peso foi reduzido com a inclusão de farinha de varredura e a conversão alimentar não foi alterada. Os níveis substituição não influenciaram os níveis de hematócrito, uréia e glicose sangüíneos.

A farinha de varredura pode ser utilizada em substituição total ao milho na alimentação de bezerros holandeses do desaleitamento até 180 dias de idade, com ganhos de pesos satisfatórios.

\section{Literatura Citada}

ARAÚJO, G.G.L.; COELHO DA SILVA, J.F.; VALADARES FILHO et al. Ganho de peso, conversão alimentar e características da carcaça de bezerros alimentados com dietas contendo diferentes níveis de volumoso. Revista Brasileira de Zootecnia, v.27, n.5, p.1006-1012, 1998.

BARNES, M.A.; KAZMER. G.W.; AKERS, R.M. et al. Influence of selection for milk yield on endogenous hormones and metabolites in Holstein heifers and cows. Journal of Animal Science, v.60, n.1, p.271-284.

CALDAS NETO, S.F.; ZEOULA, L.M.; PRADO, I.N. et al. Degradabilidade ruminal de concentrados compostos com milho, raspa de mandioca e resíduos das farinheiras. In: REUNIÃO ANUAL DA SOCIEDADE BRASILEIRA DE ZOOTECNIA, 37, 2000. Viçosa. Anais... Viçosa: Sociedade Brasileira de Zootecnia, 2000b, p.378.

CAMPOS, O.F.; LIZIEIRE, R.S. Produção do bezerrão. Coronel Pacheco: EMBRAPA/CNPGL, 2000. 12p.

CEREDA, M.P. Caracterização dos resíduos da industrialização da mandioca. In: CEREDA, M.P. (Ed.) Resíduos da industrialização da mandioca. Botucatu: Paulicéia, 1994. p.11-50.

CHARLES, T.P.; CAMPOS, O.F.; LIZIEIRE, R.S. Uso do teste de coagulação pelo glutaraldeído como indicador do nível de imunoglobulinas no soro de bezerros recém nascidos. Revista da Sociedade Brasileira de Zootecnia, v.23, n.1 p.65-72, 1994.

De BEM, I.A.B. A mandioca como componente de rações comerciais. In: CONGRESSO LATINO-AMERICANO DE RAÍZES TROPICAIS, 1., 1996, São Pedro. Anais... São Pedro: 1996. p.75-77. 
DIAZ-CASTANEDA, M.; BRISSON, G.J. Blood responses of calves fed milk substitutes containing hydrolyzed fish protein and lime-treated corn flour. Journal of Dairy Science, 72:2095-2106, 1989.

GRANT, R.; STOCK, R.; MADER, T. Feeding and managing Holstein steers. 1993. Disponível na Internet http://ianrwww.unl.edu/pubs/dairy/g1177.htm

KEARL, L.C. Nutrients requirements of ruminants in developing countries. Logan: International Feedstuffs Institute, Utah Agricultural Experimental Station, Utah State University, 1982. 271p.

LUCCI, C.S. Bovinos leiteiros jovens. São Paulo: Nobel, 1989. $371 \mathrm{p}$.

MARQUES, J.A.; PRADO, I.N.; ZEOULA, L.M. et al. Avaliação da mandioca e seus resíduos industriais em substituição ao milho no desempenho de novilhas confinadas. Revista Brasileira de Zootecnia, v.29, n.5, p.1528-1536, 2000.

MARTINS, A.S.; ZEOULA, L.M.; PRADO, I.N. et al. Degradabilidade ruminal in situ da matéria seca e proteína bruta das silagens de milho e sorgo e de alguns alimentos concentrados. Revista Brasileira de Zootecnia, v.28, n.5, p.898-905, 1999.

MATSUZAKI, M.; TAKIZAWA, S.; OGAWA, M. Plasma insulin, metabolite concentrations, and carcass characteristics of Japanese Black, Japanese Brown, and Holstein steers. Journal of Animal Science, v.75, p.3287-3293, 1997.

MELLOTI, S.D. Contribuição para o estudo da composição química e valor nutritivo dos resíduos da industrialização da mandioca, Manihot utilissima, POHL., no Estado de São Paulo. Boletim de Indústria Animal, v.29, p.339-349, 1972.

NATIONAL RESEARCH COUNCIL - NRC. Nutrient requirements of dairy cattle. Washington, D.C., 1988. 158p.

NEATHERY, M.W.; CROWE, C.T.; HARTNELL, G.F. et al. Effects of sometribove on performance, carcass composition, and chemical blood characteristics of dairy calves. Journal of Dairy Science, v.74, p.3933-3939, 1991.

PEIXOTO, R.R.; WARNER, R.G. Avaliação da farinha de mandioca como componente de rações para terneiros leiteiros e desaleitamento precoce. Revista Brasileira de Mandioca, v.12, n.1/2, p.39-47, 1997.

PARK, C.S. Influence of dietary protein on blood cholesterol and related metabolites of growing calves. Journal of Animal Science, v.61, n.4, p.924-930, 1985.
PEREIRA, J.R.A.; ROSSI Jr., P. Manual prático de avaliação nutricional de alimentos. Piracicaba: Fundação de Estudos Agrários "Luiz de Queiroz", 1995. 25p.

POORE, M.H.; ECK, T.P.; SWINGLE, R.S. et al. Total starch and relative starch availability of feed grains. In: BIENNIAL CONFERENCE ON RUMEN FUNCTION, 1989, Chicago. Abstract... Chicago: 1989. (Abstract, 35)

PRADO, I.N. Substituição gradativa do leite integral de vaca pelo leite de soja com adição de $3 \%$ de gordura de porco no aleitamento artificial de bezerros holandesados. Lavras: Universidade Federal de Lavras, 1981. Dissertação (Mestrado em Zootecnia) - Universidade Federal de Lavras, 1981.

SALLES, M.S.V.; LUCCI, C.S. Monensina para bezerros ruminantes em crescimento acelerado. In: REUNIÃO ANUAL DA SOCIEDADE BRASILEIRA DE ZOOTECNIA, 33., 1998, Botucatu. Anais... Botucatu: Sociedade Brasileira de Zootecnia, 1998. p.446-448.

SIGNORETTI, R.D.; COELHO DA SILVA, J.F.; VALADARES FILHO, S.C. et al. Consumo e digestibilidade aparente, em bezerros holandeses alimentados com dietas contendo diferentes níveis de volumoso. In: REUNIÃO ANUAL DA SOCIEDADE BRASILEIRA DE ZOOTECNIA, 33., 1998. Botucatu. Anais... Botucatu: Sociedade Brasileira de Zootecnia, 1998. p.422-424.

SILVA, D.J. Análise de alimentos: métodos químicos e biológicos. Viçosa: Universidade Federal de Viçosa, 1990. 165p.

SNIFFEN, C.J.; O'CONNOR, J.D.; VAN SOEST, P.J. et al. A net carbohydrate and protein system for evaluating cattle diets II. Carbohydrate and protein availability. Journal of Animal Science, v.70, n.11, p.3562-3577.

UNIVERSIDADE FEDERAL DE VIÇOSA - UFV. SAEG Sistema de análises estatísticas e genéticas. Viçosa, $\mathrm{MG}$ : 1983. (Manual do usuário).

Van SOEST, P.J. Nutritional ecology of ruminant. New York: Cornell University Press, 1994. 476p.

Recebido em: 31/10/00 Aceito em: 06/08/01 